\title{
Source of Bright Near-Infrared Luminescence in Gold Nanoclusters
}

Qi Li ${ }^{1 \#^{*}}$, Charles J. Zeman IV"\#, George C. Schatz² , and X. Wendy Gu ${ }^{1 *}$

${ }^{1}$ Department of Mechanical Engineering, Stanford University, Stanford, CA 94305, United States

${ }^{2}$ Department of Chemistry, Northwestern University, Evanston, IL 60208, United States

\section{Contents}

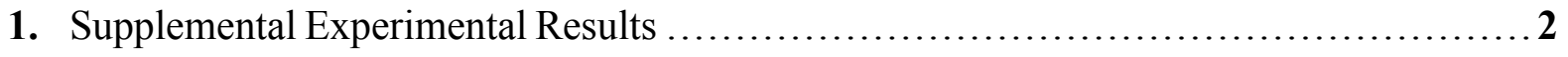

2. Molecular Orbital Analysis of Model Compounds ..................................... 5

3. Computational Results with Included Ligands .................................. 10

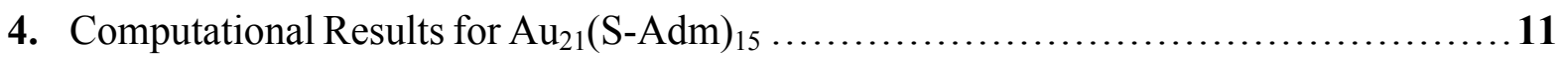

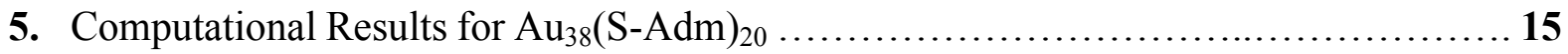

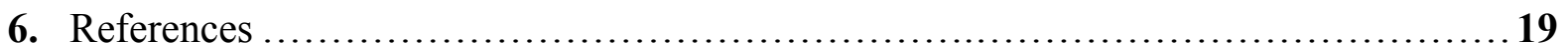




\section{Supplemental Experimental Results.}

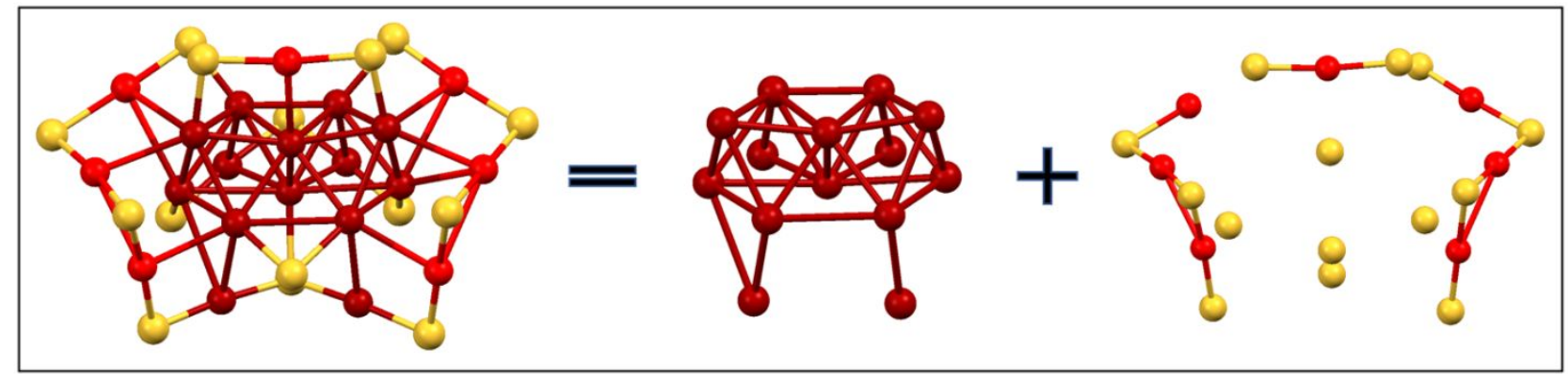

Figure S1. Anatomy of the atomic structure of $\mathrm{Au}_{21}(\mathrm{~S}-\mathrm{Adm})_{15}$, which is composed of a quasi-fcc "13-1+2" Au kernel and protected by two $\mathrm{Au}_{3} \mathrm{~S}_{4}$, one $\mathrm{AuS}_{2}$ and five bridging $\mathrm{S}$ surface motifs.

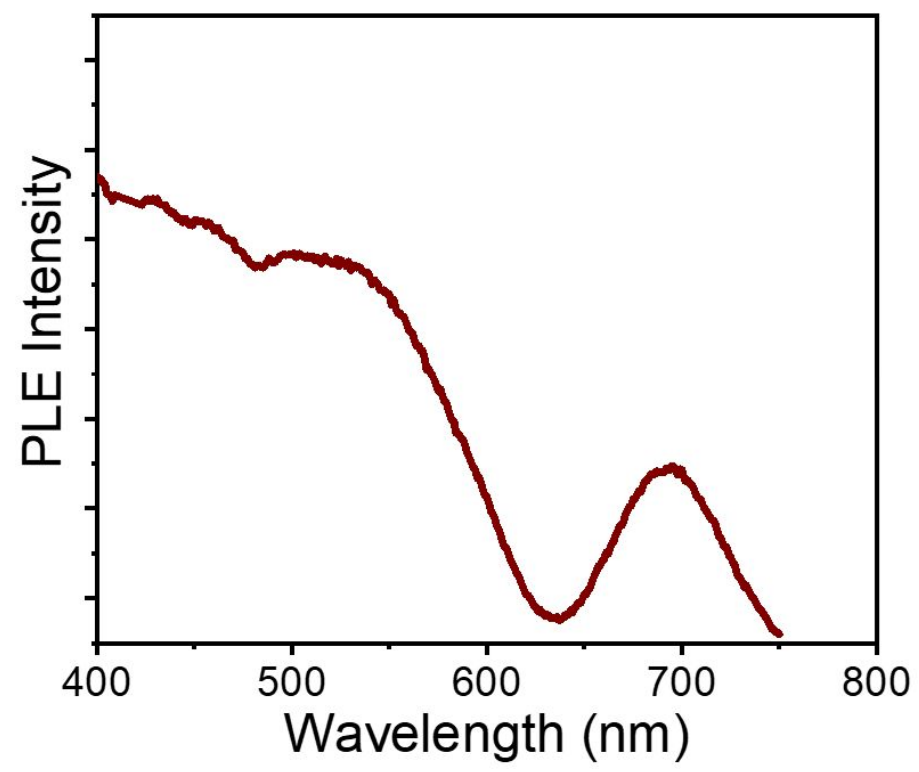

Figure S2. PLE spectrum (detected at $840 \mathrm{~nm}$ ) of $\mathrm{Au}_{21}(\mathrm{~S}-\mathrm{Adm})_{15}$. 

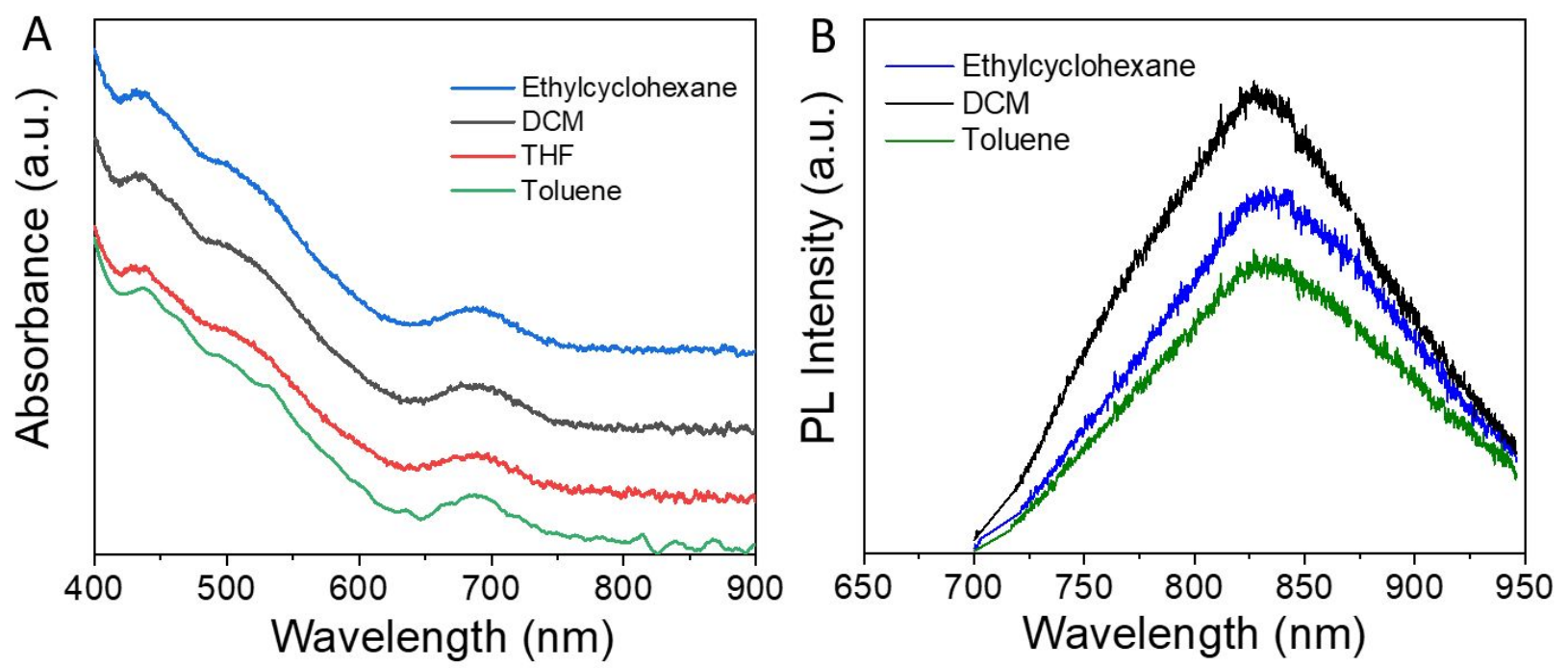

Figure S3. Absorption and $\mathrm{PL}$ of $\mathrm{Au}_{21}(\mathrm{~S}-\mathrm{Adm})_{15}$.in solvents with different polarities.

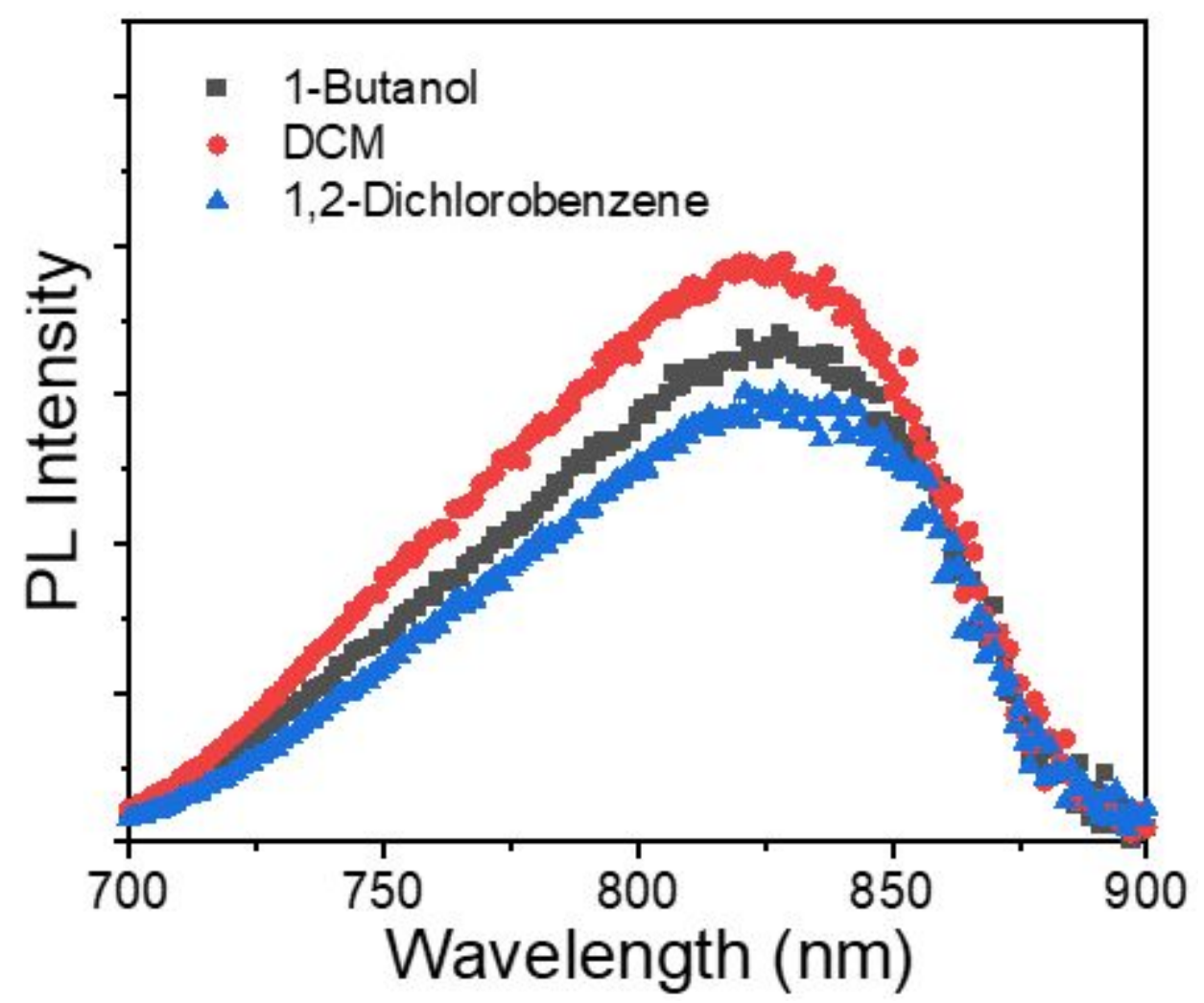

Figure S4. PL of $\mathrm{Au}_{21}(\mathrm{~S}-\mathrm{Adm})_{15}$. in solvents with different viscosities. 

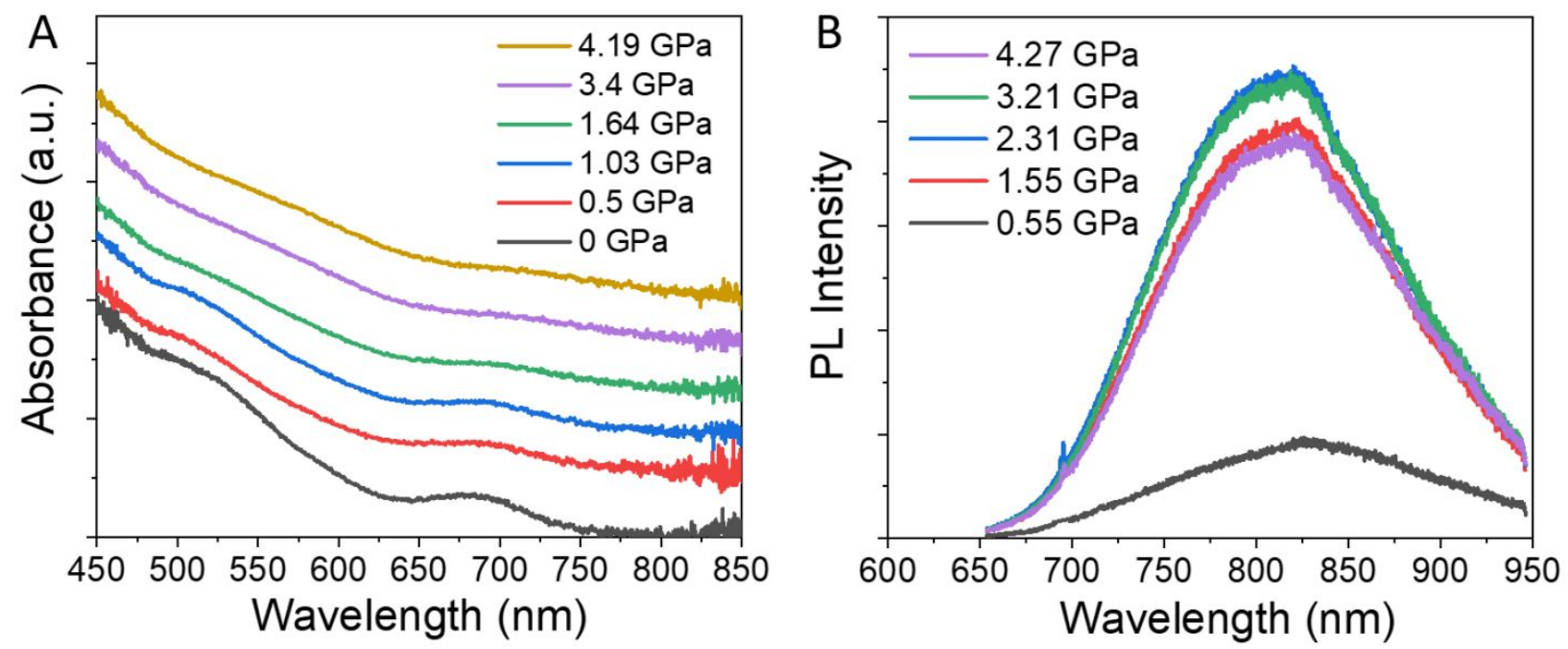

Figure S5. Pressure-dependent absorption and PL spectra of $\mathrm{Au}_{21}(\mathrm{~S}-\mathrm{Adm})_{15}$ in Toluene (nonhydrostatic).
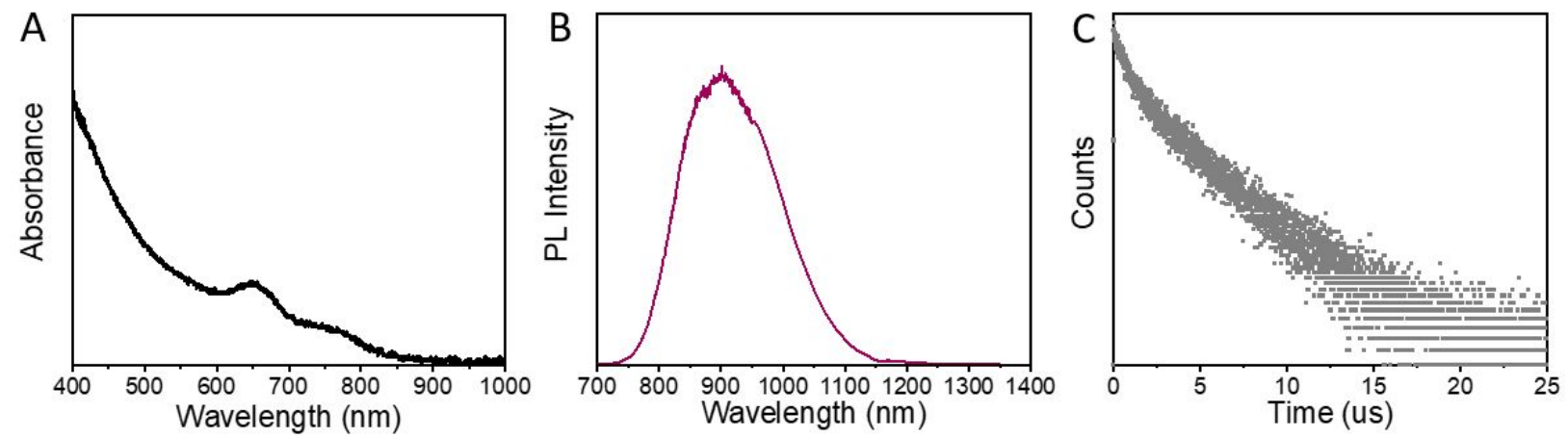

Figure S6. Absorption, PL and TCSPC trajectory of $\mathrm{Au}_{38} \mathrm{~S}_{2}(\mathrm{~S}-\mathrm{Adm})_{20}$ in DCM. 


\section{Molecular Orbital Analysis of Model Compounds.}

The effects of high pressure on the electronic structure of a series of small gold complexes were simulated by compressing the atomic coordinates by a scale factor. The scale factor was derived from the breathing mode of the Hessian taken from a frequency calculation. To achieve these results, the methodology was adapted from previous work. ${ }^{1}$ Briefly, the total energy, $\mathrm{E}_{\text {tot }}$, as a function of a small displacement, $\Delta \vec{R}$, of the atomic coordinates from their equilibrium positions, $\vec{R}^{0}$, can be described by the equation

$$
E_{\text {tot }}\left(\vec{R}^{0}+\Delta \vec{R}\right) \approx E_{\text {tot }}\left(\vec{R}^{0}\right)+\frac{1}{2} \sum_{\substack{I=1 \\ J=1 \beta=1}}^{n, n} \sum_{\substack{\alpha=1 \\ I}}^{3,3} \vec{R}_{I} \emptyset_{\alpha, \beta}\left(\Delta \vec{R}_{I}, \Delta \vec{R}_{J}\right) \Delta \vec{R}_{J}
$$

where I and J are atom labels, $\alpha$ and $\beta$ are the Cartesian directions, and $\emptyset_{\alpha, \beta}\left(\Delta \vec{R}_{I}, \Delta \vec{R}_{J}\right)$ are the Hessian matrix elements,

$$
\emptyset_{\alpha, \beta}\left(\Delta \vec{R}_{I}, \Delta \vec{R}_{J}\right)=\frac{\partial^{2} V}{\partial R_{I, \alpha} \partial R_{J, \beta}}
$$

where the second partial derivative of the potential energy of the system, $\mathrm{V}$, is taken at the equilibrium geometry.

By diagonalizing the Hessian matrix, the displacement of each atom for a specific normal mode, $L$, can be extracted. In so doing, the resultant vector quantity, $\Delta \vec{R}_{L}^{\prime 2}$, can be used to scale the atomic coordinates accordingly. This was done using the calculated frequency corresponding to the breathing mode for the molecule. In this way, the molecule can be compressed in an energetically uniform fashion (i.e. the burden of energy-change is divided equally among all bonds). A percent scale factor was used such that a value of 0.90 shows that the total sum of all bond lengths was reduced to $90 \%$ of the sum of the equilibrium bond lengths. 

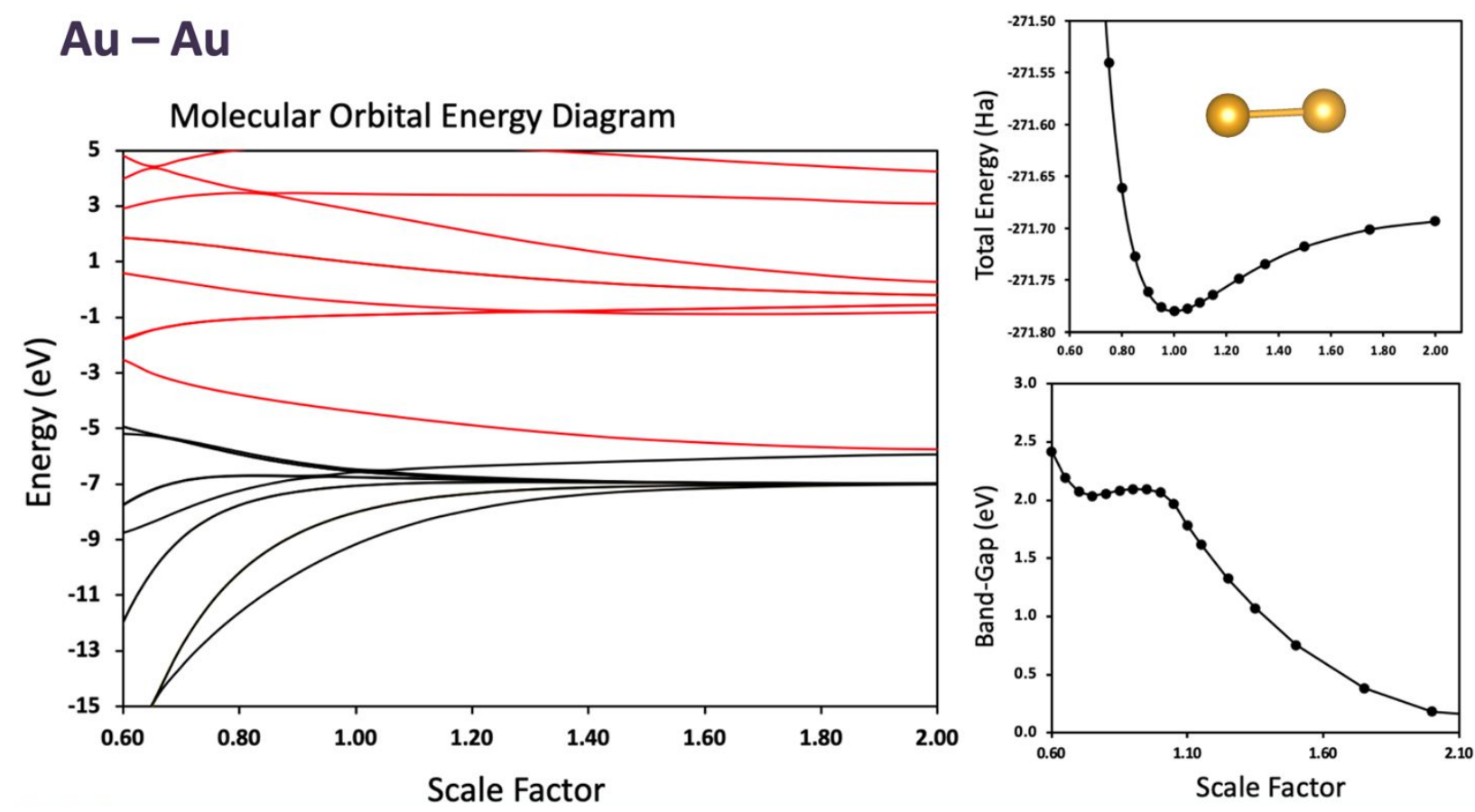

Figure S7. The molecular orbital (MO) energy diagram for digold as a function of the scale factor where 1.00 indicates the equilibrium geometry and 0.90 indicates $90 \%$ of the equilibrium bond lengths. Red lines represent unoccupied MOs and black lines are occupied MOs. The total energy and band gap of digold as a function of the scale factor are shown to the right.

\section{$\mathrm{Au}_{4}$-Square}
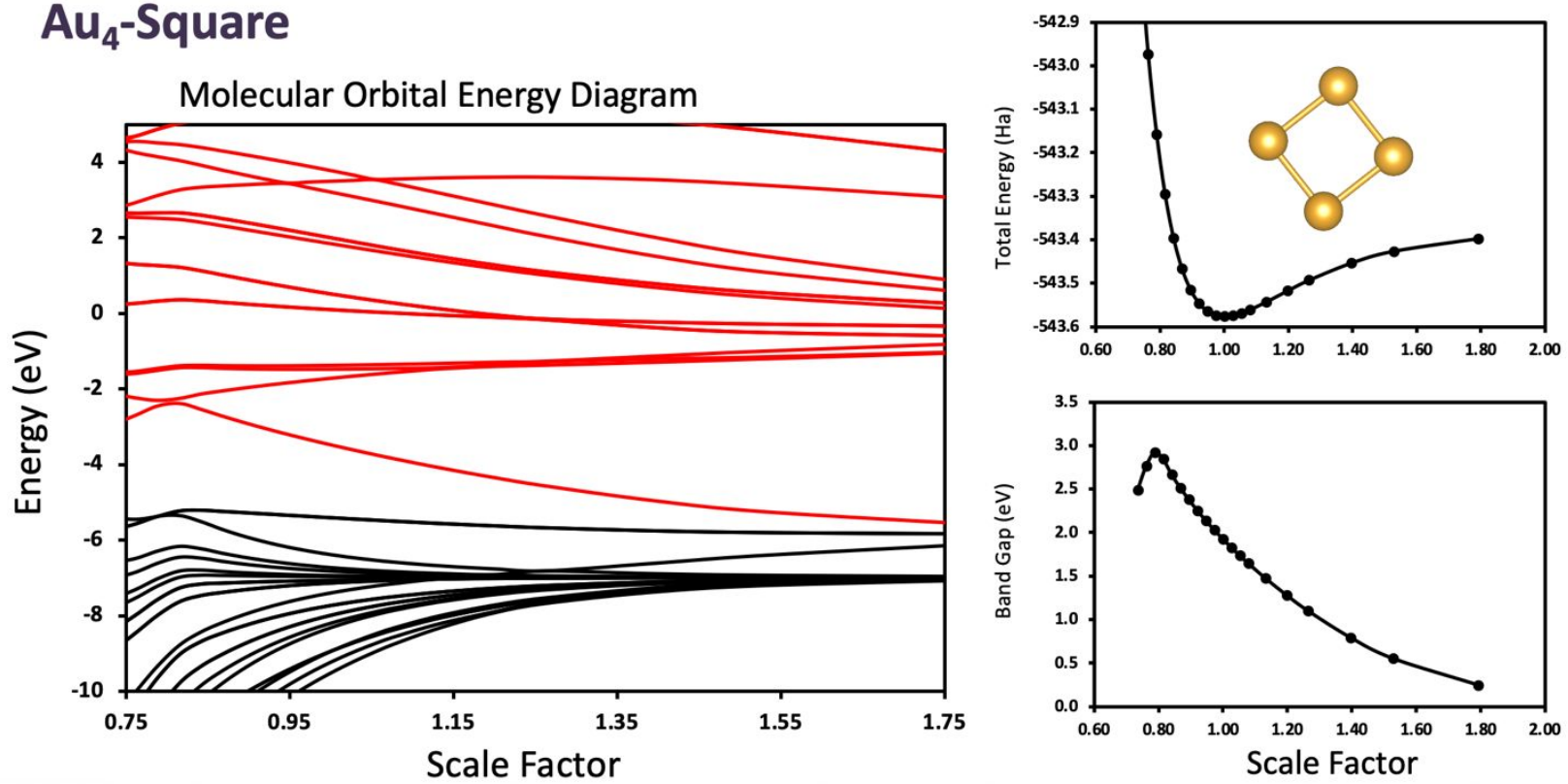

Figure S8. The MO energy diagram for tetragold as a function of the scale factor where 1.00 indicates the equilibrium geometry and 0.90 indicates $90 \%$ of the equilibrium bond lengths. Red lines represent unoccupied MOs and black lines are occupied MOs. The total energy and band gap of tetragold as a function of the scale factor are shown to the right. 

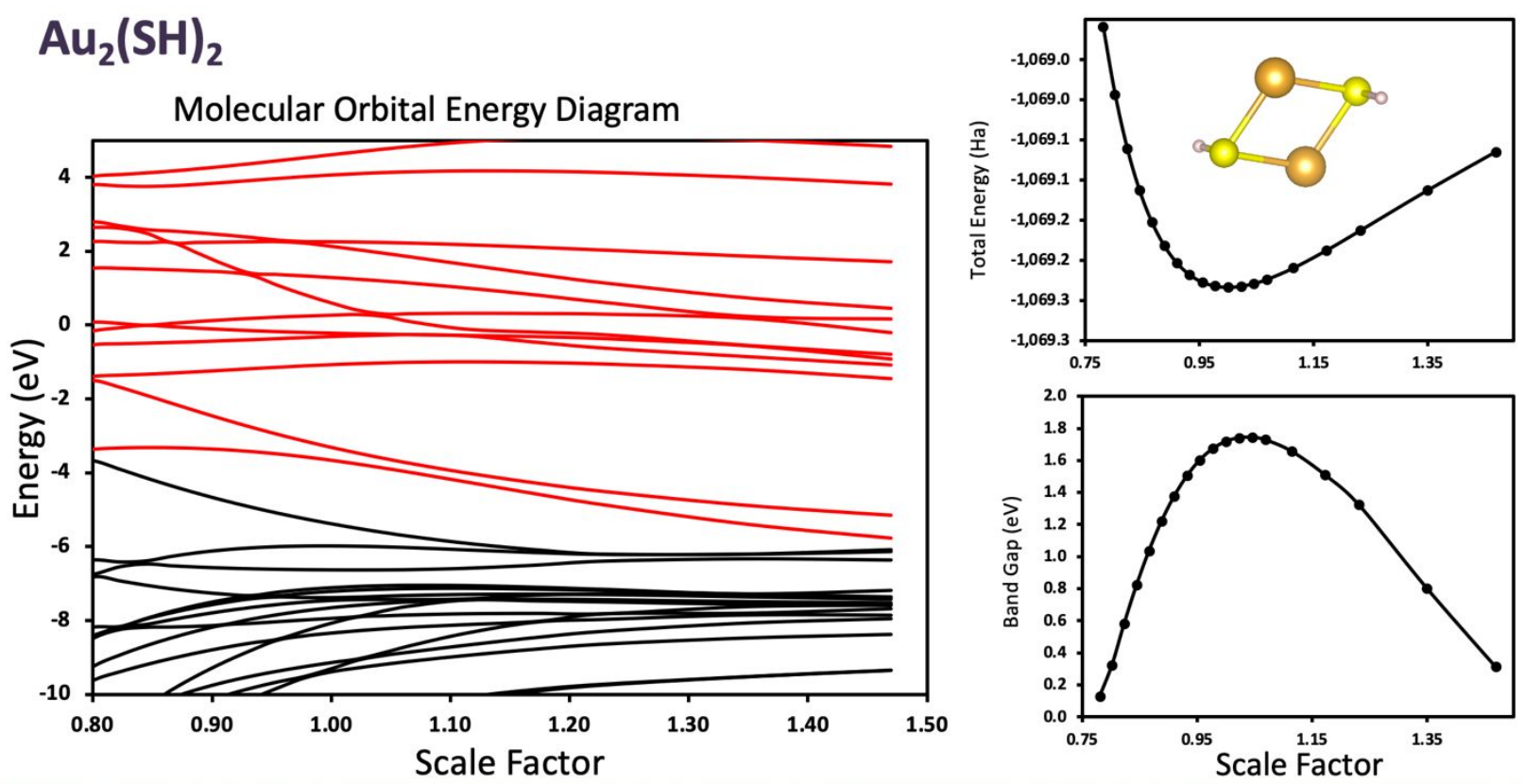

Figure S9. The MO energy diagram for $\mathrm{Au}_{2}(\mathrm{SH})_{2}$ as a function of the scale factor where 1.00 indicates the equilibrium geometry and 0.90 indicates $90 \%$ of the equilibrium bond lengths. Red lines represent unoccupied MOs and black lines are occupied MOs. The total energy and band gap of $\mathrm{Au}_{2}(\mathrm{SH})_{2}$ as a function of the scale factor are shown to the right.

\section{$\left(\mathrm{PH}_{3}\right)-\mathrm{Au}-\mathrm{Au}-\left(\mathrm{PH}_{3}\right)$}



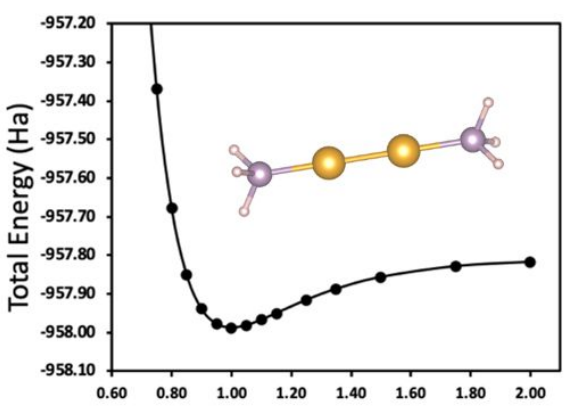

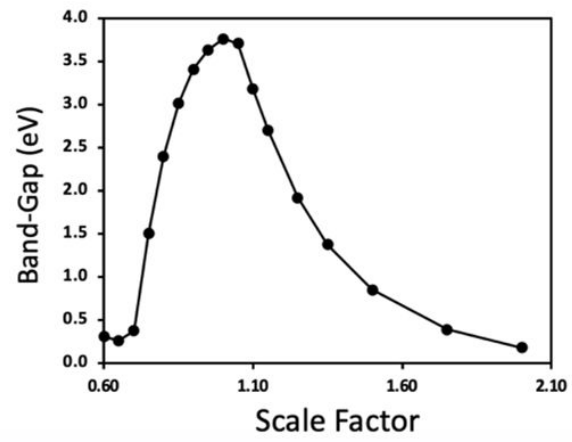

Figure S10. The MO energy diagram for $\mathrm{Au}_{2}\left(\mathrm{PH}_{3}\right)_{2}$ as a function of the scale factor where 1.00 indicates the equilibrium geometry and 0.90 indicates $90 \%$ of the equilibrium bond lengths. Red lines represent unoccupied MOs and black lines are occupied MOs. The total energy and band gap of $\mathrm{Au}_{2}\left(\mathrm{PH}_{3}\right)_{2}$ as a function of the scale factor are shown to the right. 


\section{$\left(\mathrm{C}_{2} \mathrm{H}_{4}\right)-\mathrm{Au}-\mathrm{Au}-\left(\mathrm{C}_{2} \mathrm{H}_{4}\right)$}
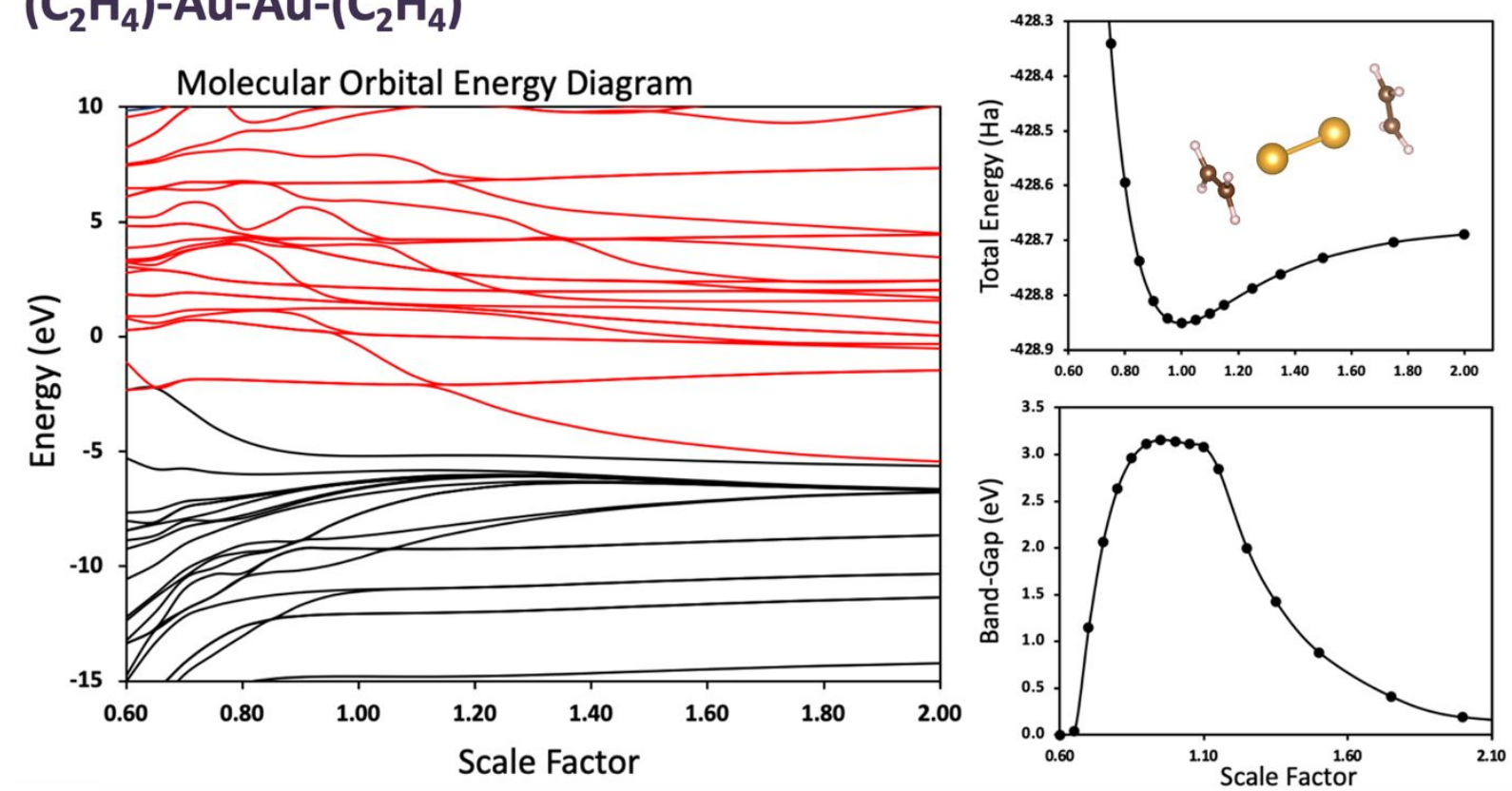

Figure S11. The MO energy diagram for $\mathrm{Au}_{2}\left(\mathrm{C}_{2} \mathrm{H}_{4}\right)_{2}$ as a function of the scale factor where 1.00 indicates the equilibrium geometry and 0.90 indicates $90 \%$ of the equilibrium bond lengths. Red lines represent unoccupied MOs and black lines are occupied MOs. The total energy and band gap of $\mathrm{Au}_{2}\left(\mathrm{C}_{2} \mathrm{H}_{4}\right)_{2}$ as a function of the scale factor are shown to the right.
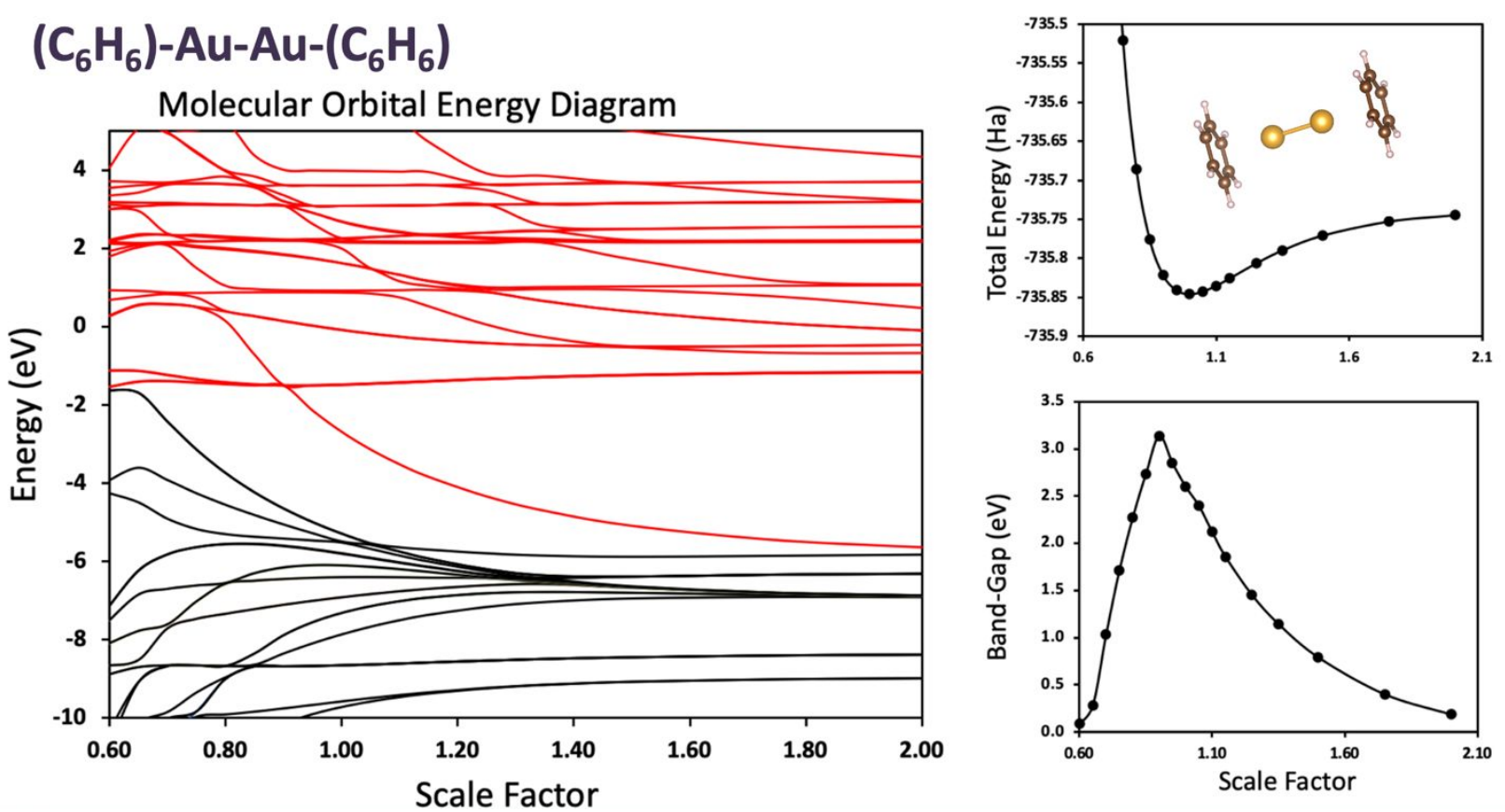

Figure S12. The MO energy diagram for $\mathrm{Au}_{2}\left(\mathrm{C}_{6} \mathrm{H}_{6}\right)_{2}$ as a function of the scale factor where 1.00 indicates the equilibrium geometry and 0.90 indicates $90 \%$ of the equilibrium bond lengths. Red lines represent unoccupied MOs and black lines are occupied MOs. The total energy and band gap of $\mathrm{Au}_{2}\left(\mathrm{C}_{6} \mathrm{H}_{6}\right)_{2}$ as a function of the scale factor are shown to the right. 

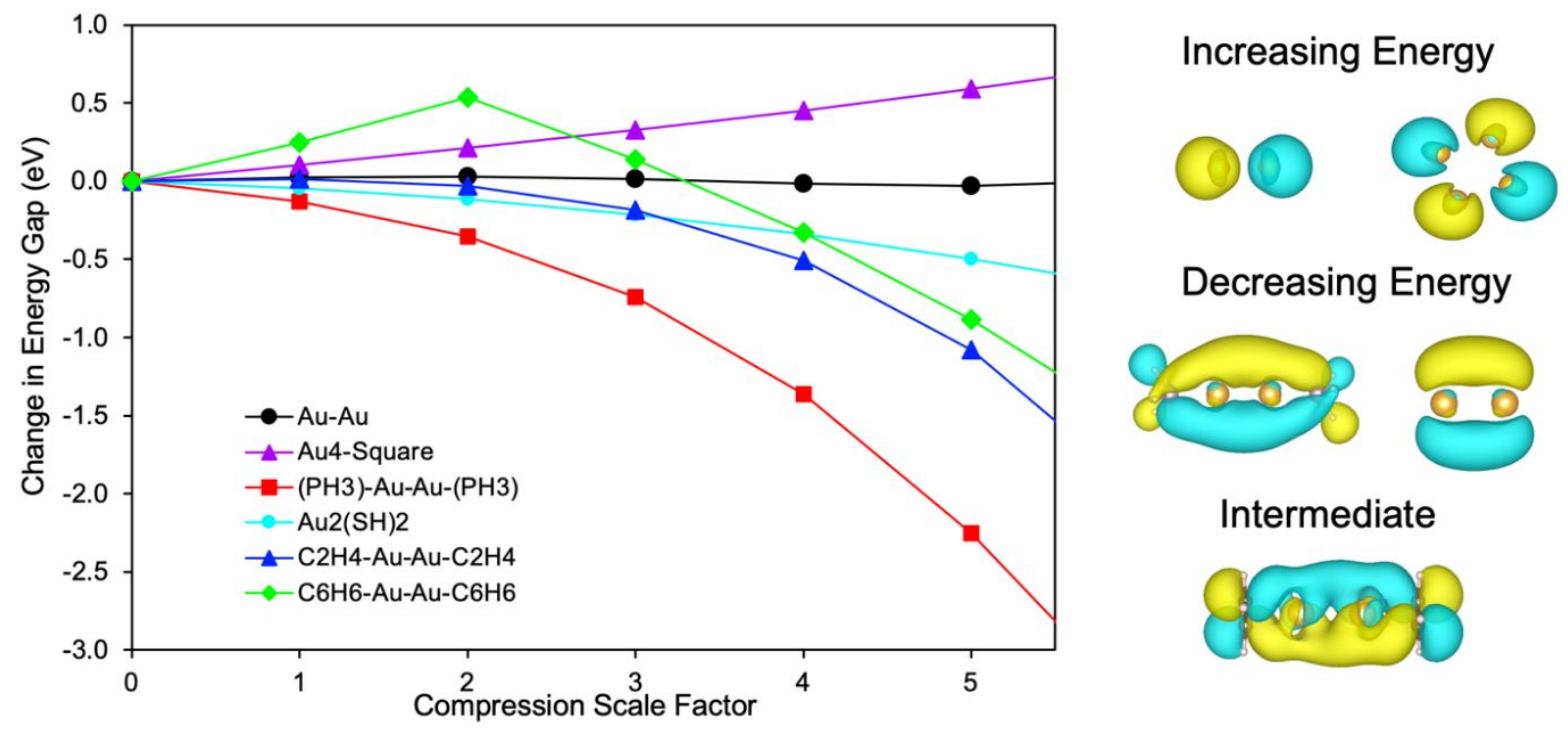

Figure S13. Change in the band gap for the model gold complexes as a function of a normalized compression scale factor where 0 indicates the equilibrium geometry and 1 indicates a $5 \%$ reduction in the sum of the bond lengths. Example MOs are shown to the right that were found to increase (antibonding MOs), decrease (bonding MOs), or remain constant as a function of molecular compression. 


\section{Computational Results with Included Ligands.}

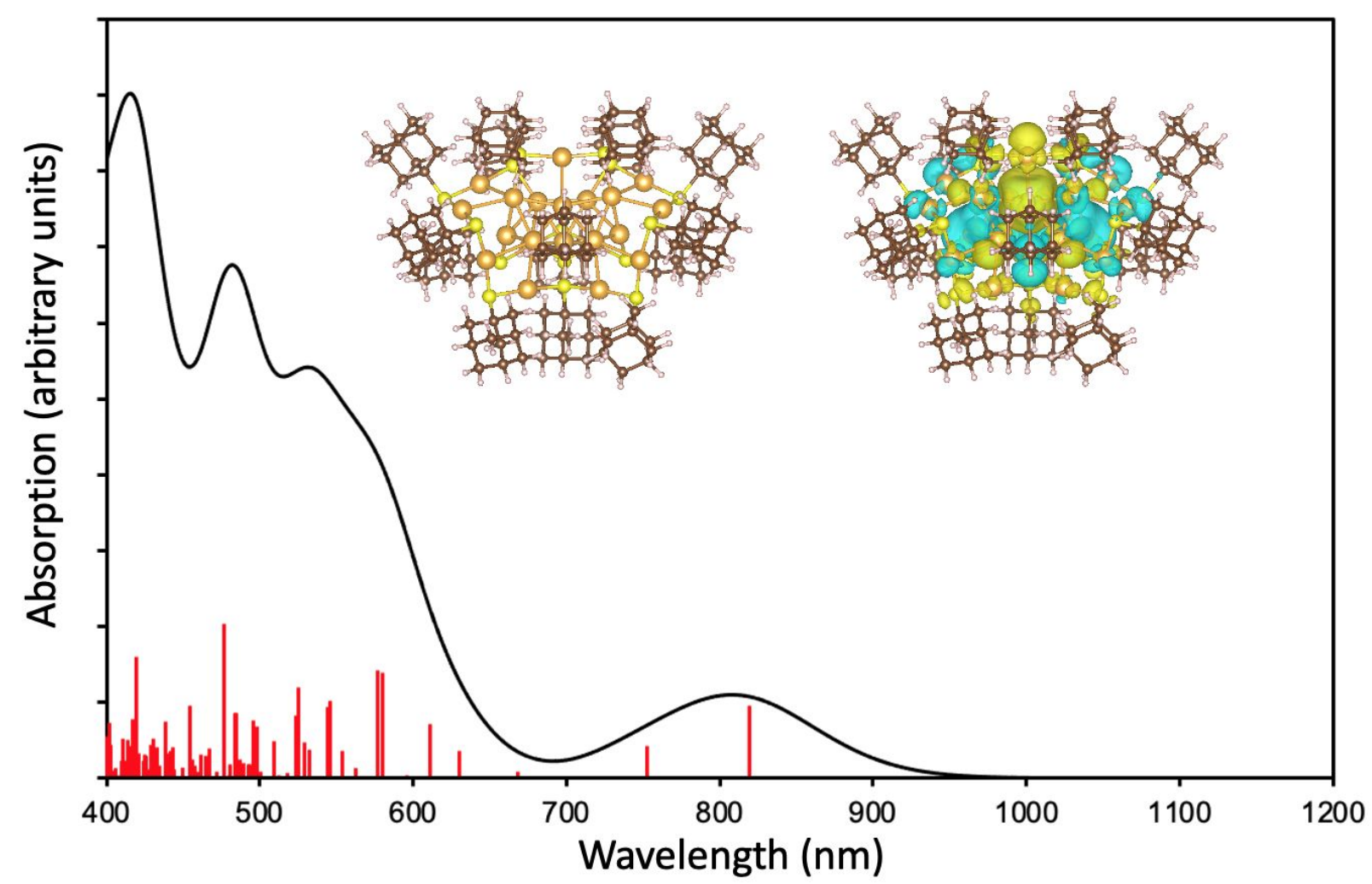

Figure S14. Calculated absorption spectrum (black line) of the complete $\mathrm{Au}_{21}(\mathrm{~S}-\mathrm{Adm})_{15}$ structure, ligands included, convoluted from the stick spectrum (red lines). The inset shows the optimized geometry and charge difference density of $\mathrm{S}_{1}$, which displays minimal contribution from the SAdm ligands. Excitation energies are only moderately red-shifted from what was reported in the main text. 


\section{Computational Results for $\mathrm{Au}_{21}(\mathrm{~S}-\mathrm{Adm})_{15}$}

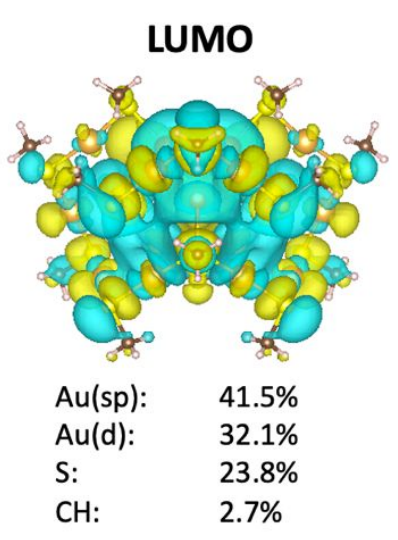

HOMO - 2

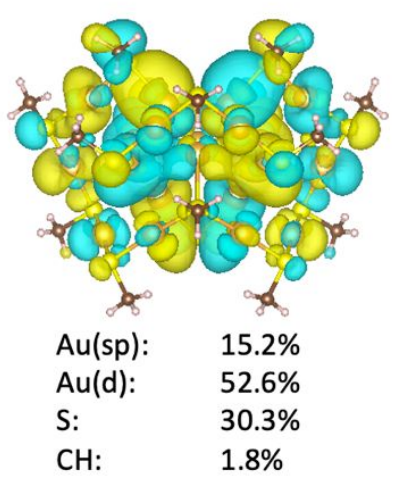

LUMO + 1

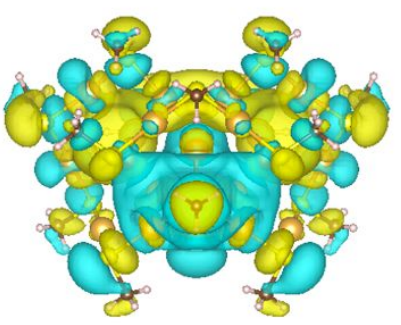

$\mathrm{Au}(\mathrm{sp}): \quad 37.4 \%$

$\mathrm{Au}(\mathrm{d}): \quad 27.8 \%$

S: $\quad 28.4 \%$

$\mathrm{CH}:$

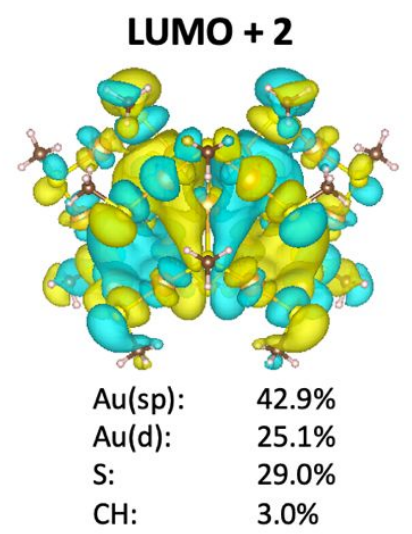

HOMO - 1

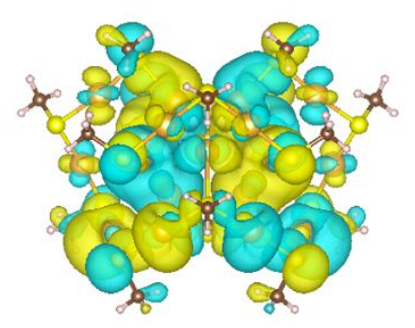

$\begin{array}{ll}\text { Au(sp): } & 26.4 \% \\ \text { Au(d): } & 46.1 \% \\ \text { S: } & 26.4 \% \\ \text { CH: } & 1.2 \%\end{array}$

HOMO



$\mathrm{Au}(\mathrm{sp}): \quad 43.9 \%$

$\mathrm{Au}(\mathrm{d}): \quad 37.7 \%$

S: $\quad 17.3 \%$

$\mathrm{CH}: \quad 1.1 \%$

Figure S15. Molecular orbitals (MO) involved in the four lowest-lying excited singlet states as identified from TDDFT calculations on the optimized geometry of $\mathrm{Au}_{21}(\mathrm{~S}-\mathrm{Adm})_{15}$ with reduced ligands. The atomic contributions to each $\mathrm{MO}$ are given below.

Table S1. Composition of the four lowest-lying BP86 excited singlet states of $\mathrm{Au}_{21}(\mathrm{~S}-\mathrm{Adm})_{15}$ with reduced ligands for the optimized ground state and excited state geometry, $1.0 \mathrm{GPa}, 2.5 \mathrm{GPa}$, and $5.0 \mathrm{GPa}$ of pressure. 1-electron transitions are only printed if they contribute $>5.0 \%$ to the overall excited state.

\begin{tabular}{|c|c|c|c|c|c|}
\hline & Optimized Ground State ${ }^{1}$ & Optimized $S_{1}$ Geometry ${ }^{1}$ & $1.0 \mathrm{GPa}^{2}$ & $2.5 \mathrm{GPa}^{2}$ & $5.0 \mathrm{GPa}^{2}$ \\
\hline $\mathbf{S}_{1}$ & $\begin{array}{l}1.569 \mathrm{eV} \\
\text { HOMO } \rightarrow \text { LUMO }(92 \%)\end{array}$ & $\begin{array}{l}\mathbf{0 . 9 6 6} \mathbf{~ e V} \\
\text { HOMO } \rightarrow \text { LUMO (98\%) }\end{array}$ & $\begin{array}{l}1.464 \mathrm{eV} \\
\text { HOMO } \rightarrow \text { LUMO }(95 \%)\end{array}$ & $\begin{array}{l}1.365 \mathrm{eV} \\
\mathrm{HOMO} \rightarrow \text { LUMO }(96 \%)\end{array}$ & $\begin{array}{l}1.332 \mathrm{eV} \\
\text { HOMO } \rightarrow \text { LUMO }(96 \%)\end{array}$ \\
\hline $\mathbf{S}_{\mathbf{2}}$ & $\begin{array}{l}1.792 \mathrm{eV} \\
\text { HOMO-1 } \rightarrow \text { LUMO }(90 \%) \\
\text { HOMO-2 } \rightarrow \text { LUMO }(5 \%)\end{array}$ & $\begin{array}{l}1.505 \text { eV } \\
\text { HOMO-1 } \rightarrow \text { LUMO (83\%) } \\
\text { HOMO } \rightarrow \text { LUMO+2 (14\%) }\end{array}$ & $\begin{array}{l}1.715 \text { eV } \\
\text { HOMO-1 } \rightarrow \text { LUMO }(89 \%) \\
\text { HOMO-2 } \rightarrow \text { LUMO }(7 \%)\end{array}$ & $\begin{array}{l}1.673 \mathrm{eV} \\
\text { HOMO-1 } \rightarrow \text { LUMO }(94 \%)\end{array}$ & $\begin{array}{l}1.684 \mathrm{eV} \\
\text { HOMO-1 } \rightarrow \text { LUMO }(94 \%)\end{array}$ \\
\hline $\mathbf{S}_{3}$ & $\begin{array}{l}1.840 \mathrm{eV} \\
\mathrm{HOMO} \rightarrow \text { LUMO+1 }(90 \%)\end{array}$ & $\begin{array}{l}\mathbf{1 . 5 8 2} \mathrm{eV} \\
\mathrm{HOMO} \rightarrow \text { LUMO+1 }(94 \%)\end{array}$ & $\begin{array}{l}1.866 \mathrm{eV} \\
\mathrm{HOMO} \rightarrow \text { LUMO+1 (89\%) }\end{array}$ & $\begin{array}{l}1.808 \mathrm{eV} \\
\mathrm{HOMO} \rightarrow \text { LUMO+1 (91\%) }\end{array}$ & $\begin{array}{l}1.774 \mathrm{eV} \\
\mathrm{HOMO} \rightarrow \text { LUMO+1 }(92 \%)\end{array}$ \\
\hline $\mathbf{S}_{\mathbf{4}}$ & $\begin{array}{l}1.914 \mathrm{eV} \\
\text { HOMO-2 } \rightarrow \text { LUMO }(93 \%)\end{array}$ & $\begin{array}{l}1.616 \mathrm{eV} \\
\text { HOMO-2 } \rightarrow \text { LUMO (98\%) }\end{array}$ & $\begin{array}{l}1.880 \mathrm{eV} \\
\text { HOMO-2 } \rightarrow \text { LUMO }(89 \%) \\
\text { HOMO-1 } \rightarrow \text { LUMO }(6 \%)\end{array}$ & $\begin{array}{l}1.890 \mathrm{eV} \\
\text { HOMO-2 } \rightarrow \text { LUMO }(77 \%) \\
\text { HOMO } \rightarrow \text { LUMO+2 }(17 \%)\end{array}$ & $\begin{array}{l}1.900 \mathrm{eV} \\
\text { HOMO-2 } \rightarrow \text { LUMO }(39 \%) \\
\text { HOMO } \rightarrow \text { LUMO+2 }(57 \%)\end{array}$ \\
\hline
\end{tabular}

${ }^{1}$ Geometries derived from BP86. ${ }^{2}$ Geometries derived from PBE condensed-phase simulations. 

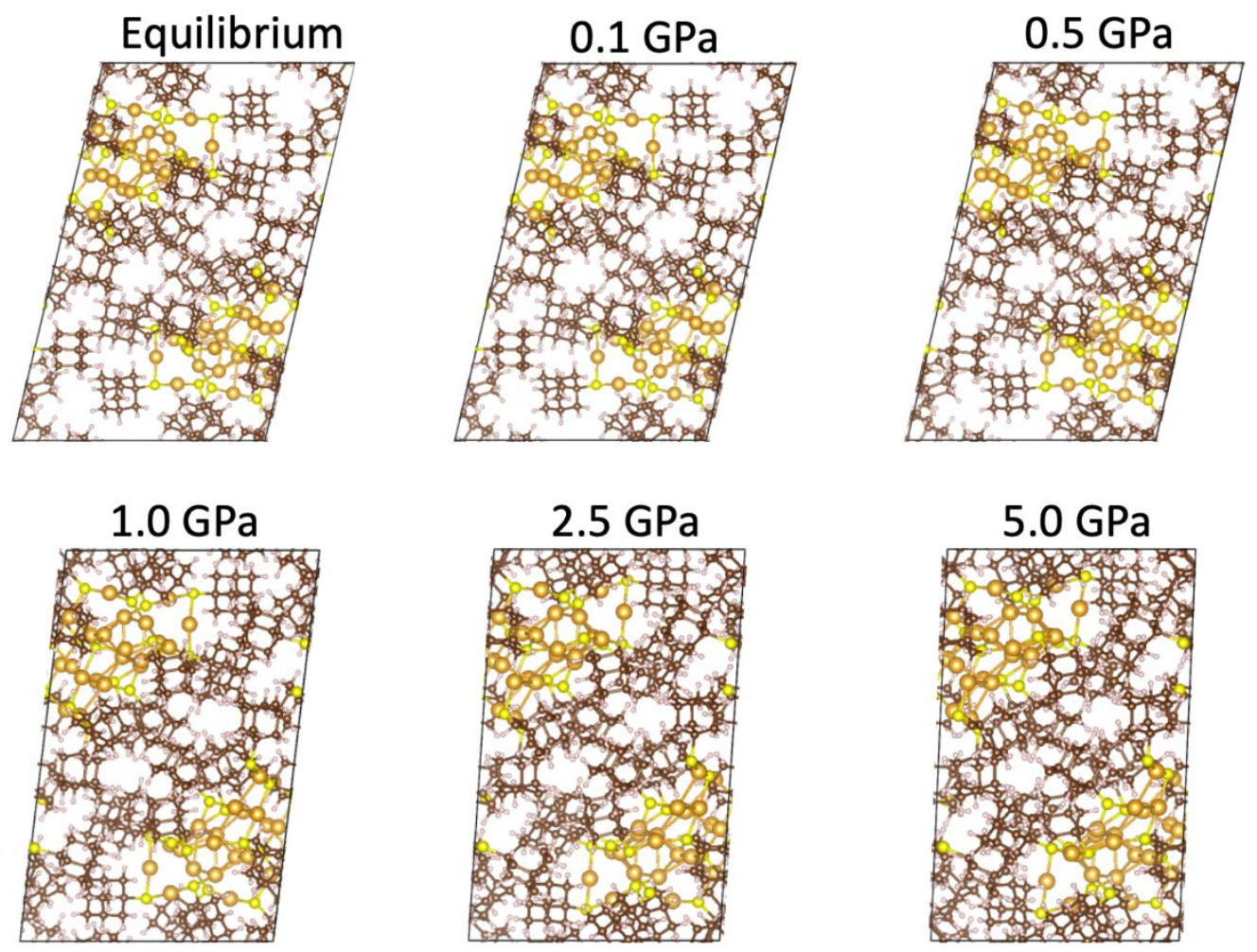

Figure S16. Optimized unit cells of $\mathrm{Au}_{21}(\mathrm{~S}-\mathrm{Adm})_{15}$ using different amounts of Pulay stress with the PBE exchange correlation functional. Cell sizes are not to scale.



Figure S17. Au-projected density of states from the $\mathrm{Au}_{21}(\mathrm{~S}-\mathrm{Adm})_{15}$ periodic unit cell using different amounts of Pulay stress with the PBE exchange correlation functional. Energies are corrected with respect to the valence band maximum (VBM). 

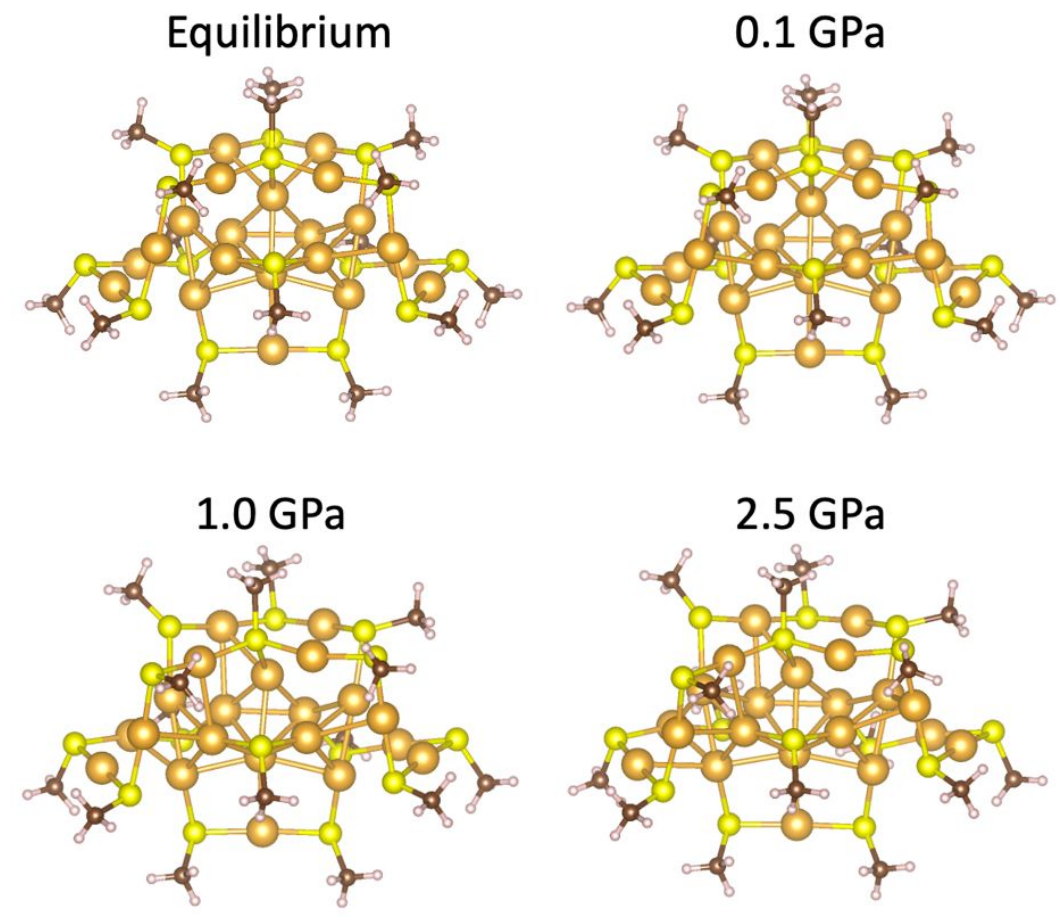

Figure S18. Structures of individual $\mathrm{Au}_{21}(\mathrm{~S}-\mathrm{Adm})_{15}$ nanoclusters extracted from the optimized unit cells.
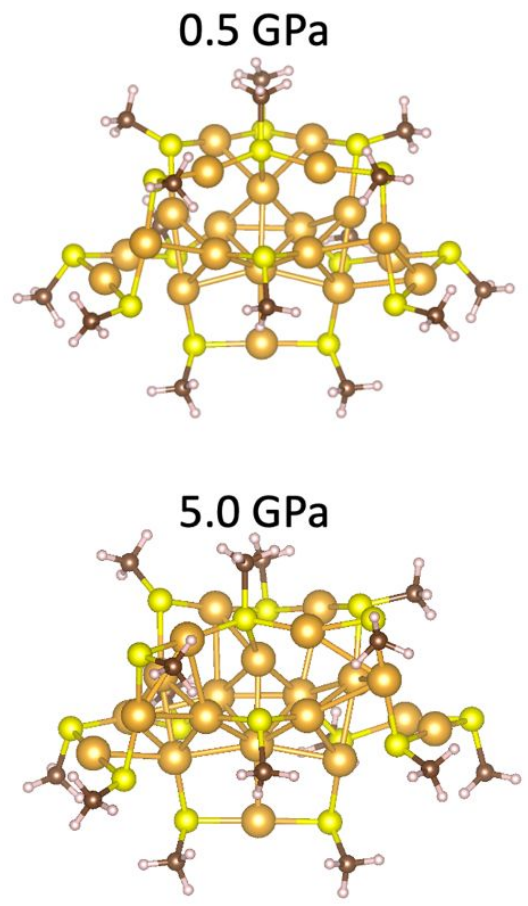

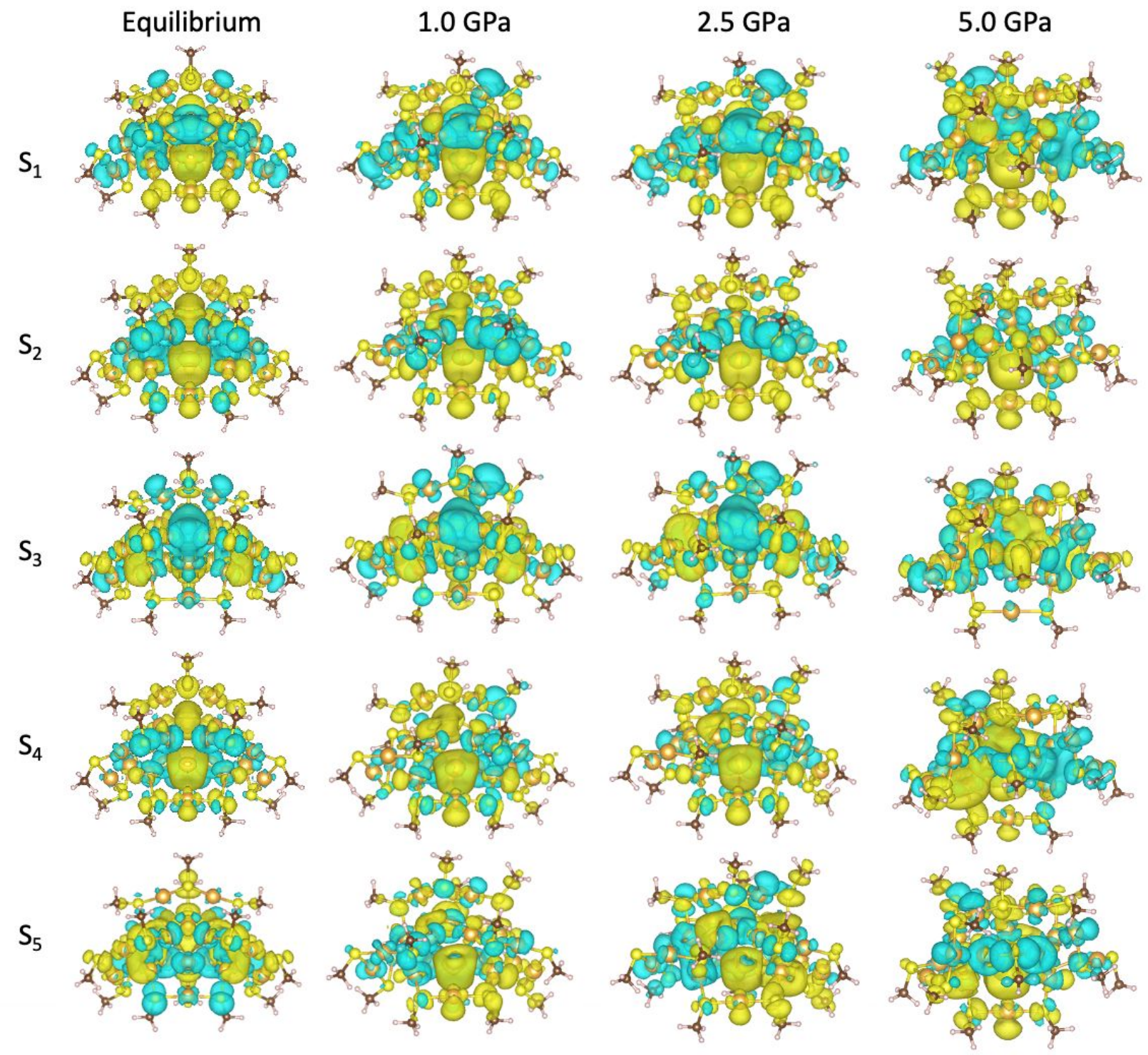

Figure S19. Charge difference densities of the first five excited states at equilibrium, $1.0 \mathrm{GPa}$, $2.5 \mathrm{GPa}$, and $5.0 \mathrm{GPa}$ of applied pressure for $\mathrm{Au}_{21}(\mathrm{~S}-\mathrm{Adm})_{15}$. Charge moves from blue to yellow orbitals upon photoexcitation. 


\section{Computational Results for $\mathrm{Au}_{38}(\mathrm{~S}-\mathrm{Adm})_{20}$}


Figure S20. Molecular orbitals (MO) involved in the four lowest-lying excited singlet states as identified from TDDFT calculations on the optimized geometry of $\mathrm{Au}_{38} \mathrm{~S}_{2}(\mathrm{~S}-\mathrm{Adm})_{20}$ with reduced ligands. The atomic contributions to each MO are given below.

Table S2. Composition of the four lowest-lying BP86 excited singlet states of $\mathrm{Au}_{38} \mathrm{~S}_{2}(\mathrm{~S}-\mathrm{Adm})_{20}$ with reduced ligands for the optimized ground state and excited state geometry, 1.0 GPa, 2.5 GPa, and 5.0 GPa of pressure. 1-electron transitions are only printed if they contribute $>5.0 \%$ to the overall excited state.

\begin{tabular}{|c|c|c|c|c|c|}
\hline & Optimized Ground State ${ }^{1}$ & 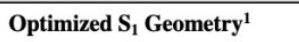 & $1.0 \mathrm{GPa}^{2}$ & $2.5 \mathrm{GPa}^{2}$ & $5.0 \mathrm{GPa}^{2}$ \\
\hline $\mathbf{S}_{1}$ & $\begin{array}{l}1.524 \text { eV } \\
\text { HOMO } \rightarrow \text { LUMO (84\%) } \\
\text { HOMO-1 } \rightarrow \text { LUMO+1 (9\%) }\end{array}$ & $\begin{array}{l}1.220 \mathrm{eV} \\
\mathrm{HOMO} \rightarrow \text { LUMO (92\%) }\end{array}$ & $\begin{array}{l}\mathbf{1 . 5 0 8} \text { eV } \\
\text { HOMO-1 } \rightarrow \text { LUMO }(61 \%) \\
\text { HOMO } \rightarrow \text { LUMO }(27 \%) \\
\text { HOMO } \rightarrow \text { LUMO+1 }(9 \%)\end{array}$ & $\begin{array}{l}1.429 \mathrm{eV} \\
\text { HOMO } \rightarrow \text { LUMO }(92 \%)\end{array}$ & $\begin{array}{l}1.213 \mathrm{eV} \\
\text { HOMO } \rightarrow \text { LUMO }(99 \%)\end{array}$ \\
\hline $\mathbf{S}_{\mathbf{2}}$ & $\begin{array}{l}1.548 \text { eV } \\
\text { HOMO-1 } \rightarrow \text { LUMO (63\%) } \\
\text { HOMO } \rightarrow \text { LUMO+1 (30\%) }\end{array}$ & $\begin{array}{l}1.394 \mathrm{eV} \\
\text { HOMO-1 } \rightarrow \text { LUMO }(81 \%) \\
\text { HOMO-2 } \rightarrow \text { LUMO }(16 \%)\end{array}$ & $\begin{array}{l}1.523 \mathrm{eV} \\
\text { HOMO } \rightarrow \text { LUMO }(54 \%) \\
\text { HOMO-1 } \rightarrow \text { LUMO }(30 \%) \\
\text { HOMO-1 } \rightarrow \text { LUMO+1 }(11 \%)\end{array}$ & $\begin{array}{l}1.492 \mathrm{eV} \\
\text { HOMO } \rightarrow \text { LUMO+1 }(53 \%) \\
\text { HOMO-1 } \rightarrow \text { LUMO }(40 \%) \\
\text { HOMO-1 } \rightarrow \text { LUMO+1 }(5 \%)\end{array}$ & $\begin{array}{l}1.238 \mathrm{eV} \\
\mathrm{HOMO} \rightarrow \mathrm{LUMO}+1(53 \%)\end{array}$ \\
\hline $\mathbf{S}_{3}$ & $\begin{array}{l}1.574 \mathrm{eV} \\
\text { HOMO-2 } \rightarrow \text { LUMO }(51 \%) \\
\text { HOMO-1 } \rightarrow \text { LUMO }(26 \%) \\
\text { HOMO } \rightarrow \text { LUMO+1 }(21 \%)\end{array}$ & $\begin{array}{l}1.449 \mathrm{eV} \\
\text { HOMO-2 } \rightarrow \text { LUMO }(48 \%) \\
\text { HOMO-3 } \rightarrow \text { LUMO }(20 \%) \\
\text { HOMO- } \rightarrow \text { LUMO }(19 \%) \\
\text { HOMO-1 } \rightarrow \text { LUMO }(8 \%)\end{array}$ & $\begin{array}{l}1.592 \mathrm{eV} \\
\text { HOMO-2 } \rightarrow \text { LUMO (91\%) }\end{array}$ & $\begin{array}{l}\mathbf{1 . 5 4 8} \mathbf{~ e V} \\
\text { HOMO- } 2 \rightarrow \text { LUMO }(91 \%) \\
\text { HOMO } \rightarrow \text { LUMO+1 }(12 \%) \\
\text { HOMO-1 } \rightarrow \text { LUMO }(9 \%)\end{array}$ & $\begin{array}{l}1.273 \mathrm{eV} \\
\mathrm{HOMO} \rightarrow \mathrm{LUMO}+2(96 \%)\end{array}$ \\
\hline $\mathbf{S}_{4}$ & $\begin{array}{l}1.619 \mathrm{eV} \\
\text { HOMO-1 } \rightarrow \text { LUMO+1 }(78 \%) \\
\text { HOMO-2 } \rightarrow \text { LUMO+1 }(14 \%)\end{array}$ & $\begin{array}{l}1.488 \mathrm{eV} \\
\text { HOMO } \rightarrow \text { LUMO+2 }(72 \%) \\
\text { HOMO-1 } \rightarrow \text { LUMO+1 }(21 \%)\end{array}$ & $\begin{array}{l}1.606 \text { eV } \\
\text { HOMO-3 } \rightarrow \text { LUMO }(77 \%) \\
\text { HOMO } \rightarrow \text { LUMO+1 }(7 \%) \\
\text { HOMO-2 } \rightarrow \text { LUMO }(6 \%)\end{array}$ & $\begin{array}{l}1.569 \mathrm{eV} \\
\mathrm{HOMO} \rightarrow \text { LUMO+2 (95\%) }\end{array}$ & $\begin{array}{l}1.441 \text { eV } \\
\text { HOMO- } 1 \rightarrow \text { LUMO }(58 \%) \\
\text { HOMO- } 1 \rightarrow \text { LUMO+2 }(23 \%) \\
\text { HOMO- } 1 \rightarrow \text { LUMO+1 }(9 \%)\end{array}$ \\
\hline
\end{tabular}

${ }^{1}$ Geometries derived from BP86. ${ }^{2}$ Geometries derived from PBE condensed-phase simulations. 
Equilibrium

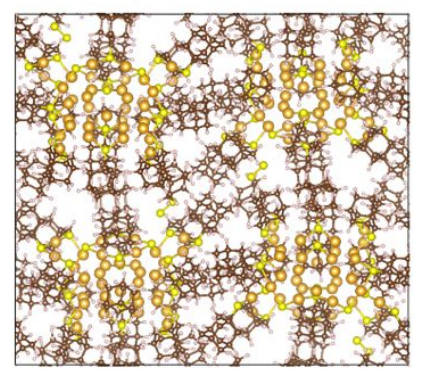

$1.0 \mathrm{GPa}$

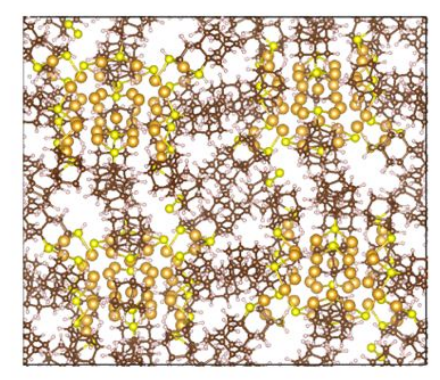

$0.1 \mathrm{GPa}$

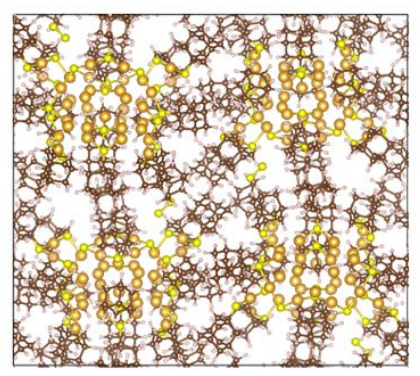

$2.5 \mathrm{GPa}$

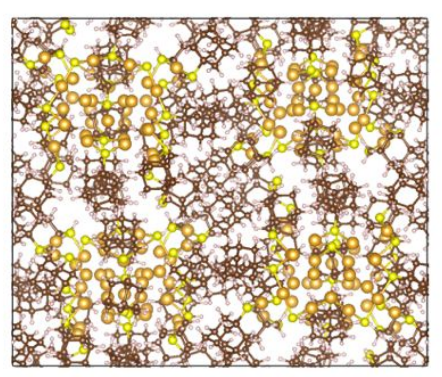

$0.5 \mathrm{GPa}$



$5.0 \mathrm{GPa}$

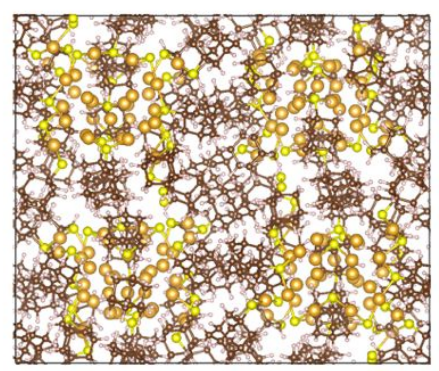

Figure S21. Optimized unit cells of $A_{3} \mathrm{~S}_{2}(\mathrm{~S}-\mathrm{Adm})_{20}$ using different amounts of Pulay stress with the PBE exchange-correlation functional. Cell sizes are not to scale.

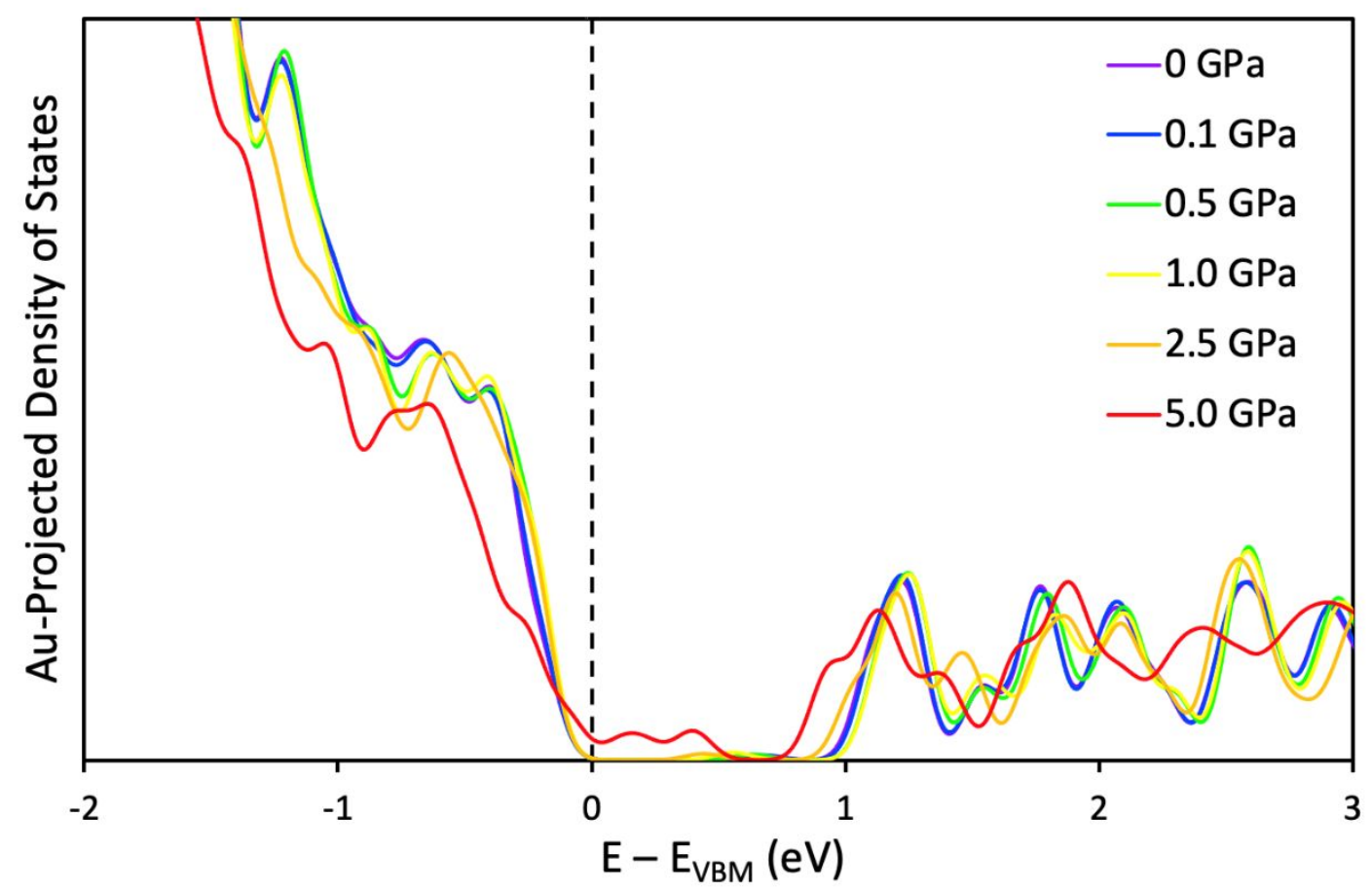

Figure S22. Au-projected density of states from the $\mathrm{Au}_{38} \mathrm{~S}_{2}(\mathrm{~S}-\mathrm{Adm})_{20}$ periodic unit cell using different amounts of Pulay stress with the PBE exchange-correlation functional. Energies are corrected with respect to the valence band maximum (VBM). 



Figure S23. Structures of individual $\mathrm{Au}_{38} \mathrm{~S}_{2}(\mathrm{~S}-\mathrm{Adm})_{20}$ nanoclusters extracted from the optimized unit cells. 
Equilibrium
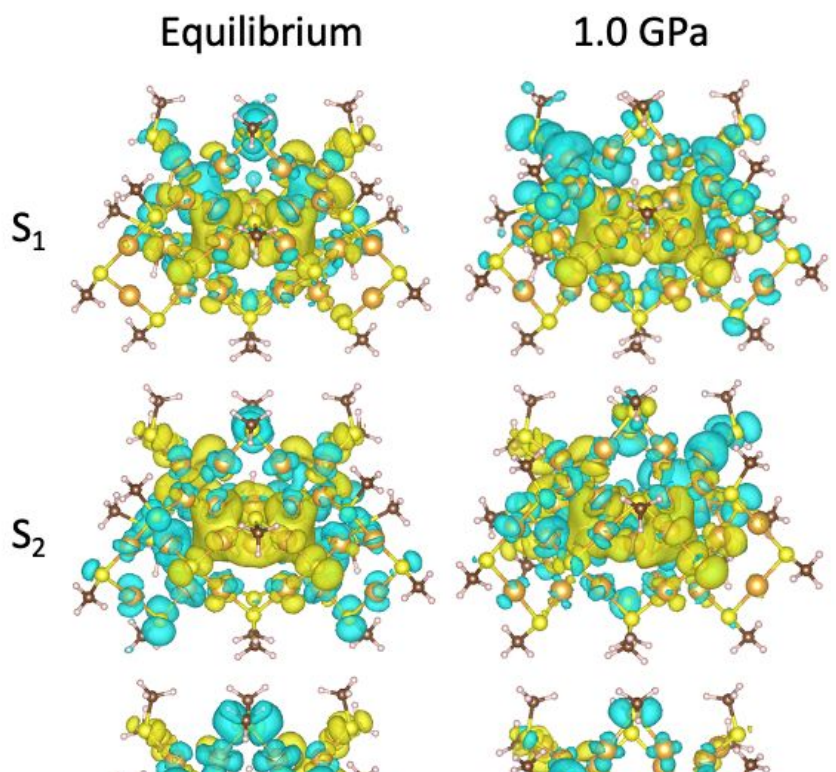

$\mathrm{S}_{3}$
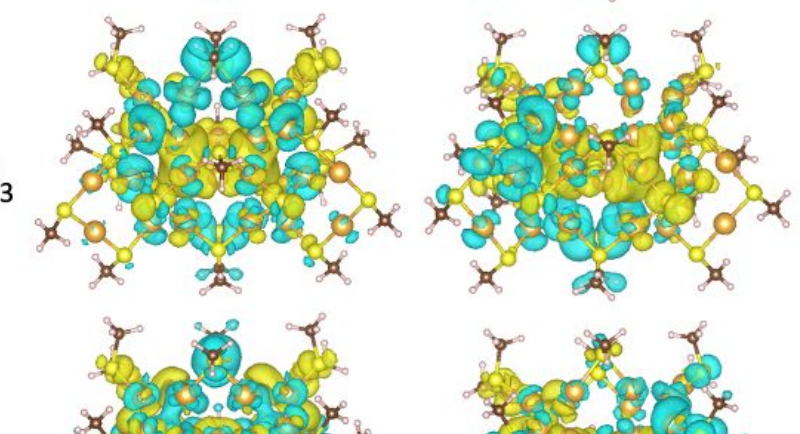

$\mathrm{S}_{4}$
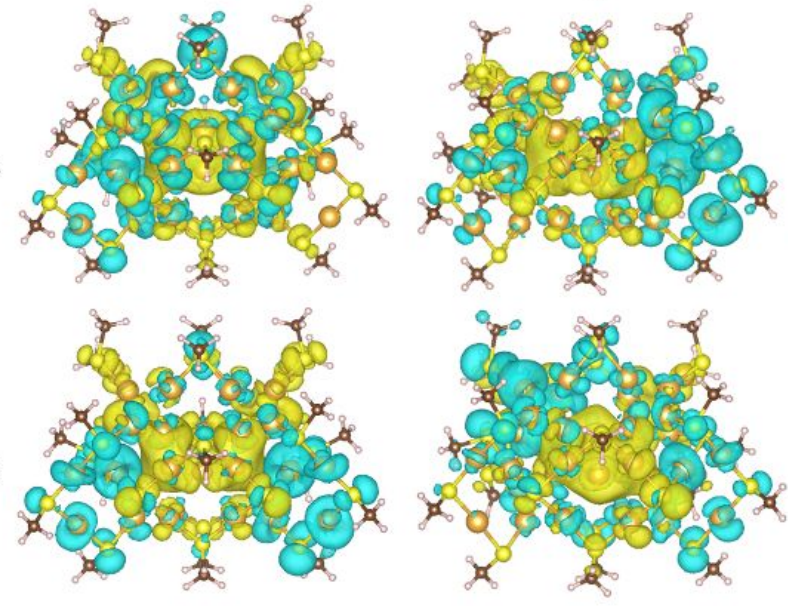

$5.0 \mathrm{GPa}$
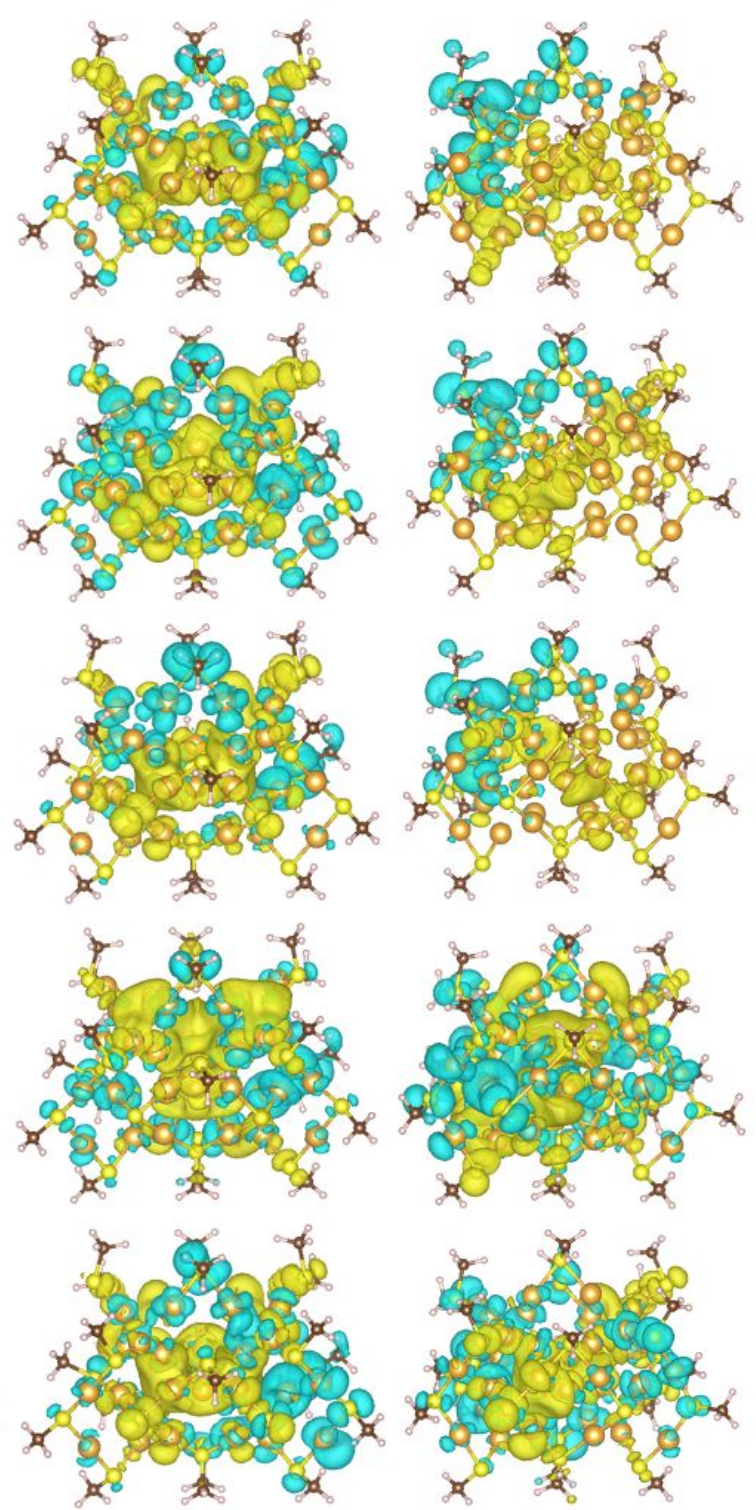

Figure S24. Charge difference densities of the first five excited states at equilibrium, 1.0 GPa, $2.5 \mathrm{GPa}$, and $5.0 \mathrm{GPa}$ of applied pressure for $\mathrm{Au}_{38} \mathrm{~S}_{2}(\mathrm{~S}-\mathrm{Adm})_{20}$. Charge moves from blue to yellow orbitals upon photoexcitation. 


\section{References}

1. Lethiec, C.M.; Madison, L. R.; Schatz, G. C. Dependence of Plasmons Energies on the Acoustic Normal Modes of $\mathrm{Ag}_{\mathrm{n}}(\mathrm{n}=20,84$, and 120) Clusters. J. Phys. Chem. C 2016, $120,20572-20578$. 